\title{
Anxiety Level of Patients Undergoing Oral Surgical Procedures
}

\author{
Sudeep Acharya, ${ }^{1}$ Sandhya Joshi, ${ }^{2}$ Amita Pradhan $^{3}$ \\ 'Department of Oral and Maxillofacial Surgery, KIST Medical College, Lalitpur, Nepal, ${ }^{2}$ National Trauma \\ Center(NAMS), Mahabauddha, Kathmandu, Nepal, ${ }^{3}$ Department of Community Medicine, KIST Medical College, \\ Lalitpur, Nepal.
}

\begin{abstract}
Background: Evidences on dental anxiety scale are essential in dental practice for better service delivery. The main objective of this study was to determine the anxiety level of patients undergoing oral surgical procedures and explore its associated factors.

Methods: This was a cross sectional study enrolling 142 patients. Semi structured questionnaire based on Corah's dental anxiety scale was prepared and administered to gather information. Descriptive statistics, chi- square test and independent $\mathrm{t}$ - test were used to analyze the data.

Results: Sixty nine percent were feeling relaxed in waiting area. Nine patients $(6.3 \%)$ were afraid of persons in white attire. About $17 \%$ reported that they were afraid of sound of dental apparatus. Many participant ( $81 \%)$ expected better outcomes of their dental procedures. When waiting for their procedure at the waiting area, about $50 \%$ stated to sense restlessness. Nearly $56 \%$ felt unease while waiting at dental chair. Nearly $70 \%$ of cases had less than 7 dental anxiety scale score indicating low anxiety to dental procedures, 23.2\% showed moderate anxiety with score of 7 to 9 and $7 \%$ showed high anxiety by scoring 10 or more out of score of 15 . Average dental anxiety scale scores did not vary as per age differences. The anxiety scores for both sexes were alike.

Conclusions: Even though anxiety level was low among the cases undergoing oral surgical procedure, being in waiting area and dental chair raises their apprehension.

Keywords: Dental anxiety; oral surgery; DAS score.
\end{abstract}

\section{INTRODUCTION}

Despite of advances in dentistry, fear of dental procedures and pain still persists globally and is a major obstacle to successful dental treatment. ${ }^{1}$

Relieving the anxiety of the patients is important prior to any treatment procedure. ${ }^{2}$ To relieve the fear of the patients, it is required to understand the anxiety level of the patients. Patients may feel anxious because of surrounding dental environment. ${ }^{3-6}$ Many studies discussed about variations in anxiety as per age, gender, communication skill of the operator and preoperative awareness of the patient. ${ }^{1,3-5,7-13}$ Many factors such as negative dental experiences, family history, use of pain relieving agents, type of extraction, experience and attire of the operator, and comorbid conditions of the patients need to be explored. Information on dental anxiety scale for Nepalese patients is a need in dental practice. This study aims to fulfill the information gap in this area. The main objective of this study was to determine the anxiety level of patients undergoing oral surgical procedures and explore its associated factors. With the results achieved, we can always analyze our shortcomings to formulate a plan to reduce anxiety during dental/oral surgery of the patients.

\section{METHODS}

This was a cross sectional study. Minimum sample size calculated was 142 at $95 \%$ confidence level, with $\sigma^{2}=3.44$, tolerable error of 0.6 units from mean and non-response rate of $12 \%$. Each day, those individuals who appeared to be odd numbered patient such as $1^{\text {st }}, 3^{\text {rd }}, 5^{\text {th }}$ and so on, were enrolled in this study till the sample size of 142 was fulfilled. The questionnaire based on Corah's dental anxiety scale ${ }^{2}$ was prepared. Three questions were asked to measure anxiety of the patients. Each response was assigned score of 1 to 5,1 being less anxious and 5 being highly anxious. The total possible scores from these three questions ranged from

Correspondence: Dr Sudeep Acharya, Department of Oral and Maxillofacial Surgery, KIST medical College, Lalitpur, Nepal. Email: drsudeepacharya@gmail. com, Phone: +9779851147241 . 
5 to 15 , the total dental anxiety scale (DAS) score was calculated for each patient. Information on age, gender, negative dental experiences, communication skill of the operator, family history, timing of dental procedures, use of pain relieving agents, type of extraction, experience and attire of the operator, preoperative awareness of the patient, comorbid conditions of the patients were collected by administering questionnaire. The questionnaire was prepared in English and translated into Nepali and retranslated into English again. One person from research team and another person other than the research team, translated the English version into Nepali independently. The discrepancies in these two sets of translated questionnaires were resolved by the two translators. Then, back translation of Nepali version to English was performed by two independent translators other than the research team members. The research team with the help of the translators, finalized the final questionnaire. Nepali language questionnaire was administered.

The data were entered in SPSS 16 and analyzed using descriptive statistics, chi-square test and independent t-test.

The ethical approval was obtained from Institutional Review Committee, KIST Medical College.

\section{RESULTS}

The mean age of patients was 40.3 years with standard deviation(SD) of 15.5 years. The age ranged from 17 to 80 years. There were $88(62 \%)$ of the females and 54 (38\%) male patients.

None of the participants were taking any medicines for other comorbid conditions. Forty five i.e., nearly $32 \%$ patients reported consumption of pain relieving medicines. Twenty i.e., about $4 \%$ patients stated that they had undergone similar dental experiences before. Ninety eight $(69 \%)$ cases said that they were comfortable in waiting area. Ninety five $(67 \%)$ patients responded that the hospital staffs explained them about the surgical procedure. Nine patients $(6.3 \%)$ were afraid of persons in white attire. Twenty four (16.9\%) patients reported that they were afraid of sound of dental apparatus.

Mean of total DAS score was 5.44 with SD 2.65. The mean scores were 1.4 with SD of $0.89,1.99$ with SD of 1.3 and 2.05 with SD of 1.21 while anticipating the dental surgery, waiting at dental office area and waiting for dental procedure on dental chair respectively.

Many participants (81\%) anticipated better outcomes of their dental procedures, $5.6 \%$ did not pay any attention to dental procedure, $7 \%$ feared of unpleasant outcome and $6.3 \%$ feel little uneasy. However, when waiting for their procedure at the waiting area, about $50 \%$ reported to feel a bit anxious or uneasiness. While waiting at dental chair, $55.6 \%$ perceived some sort of uneasiness. Nearly $70 \%$ of cases had less than score $7,23.2 \%$ showed score between 7 to 9 and $7 \%$ showed a little high anxiety by scoring 10 or more out of total score of 15 (Table1).

Table 1. Anxiety level of the patients at different instances and total DAS score.

\begin{tabular}{|c|c|c|}
\hline DAS items & Frequency & Percent \\
\hline \multicolumn{3}{|c|}{ Anticipation prior to dental treatment } \\
\hline $\begin{array}{l}\text { I would look forward to it } \\
\text { as a reasonably enjoyable } \\
\text { experience }\end{array}$ & 115 & 81 \\
\hline $\begin{array}{l}\text { I would not care one way or } \\
\text { the other }\end{array}$ & 8 & 5.6 \\
\hline $\begin{array}{l}\text { I would be little uneasy about } \\
\text { it }\end{array}$ & 9 & 6.3 \\
\hline $\begin{array}{l}\text { I would be afraid that it would } \\
\text { be unpleasant and painful }\end{array}$ & 10 & 7 \\
\hline $\begin{array}{l}\text { I would be very frightened of } \\
\text { what the dentist might do }\end{array}$ & - & - \\
\hline \multicolumn{3}{|l|}{ Waiting in dental waiting area } \\
\hline Relaxed & 75 & 52.8 \\
\hline A little uneasy & 28 & 19.7 \\
\hline Tense & 5 & 3.5 \\
\hline Anxious & 33 & 23.2 \\
\hline $\begin{array}{l}\text { So anxious that I sometimes } \\
\text { break out in sweat or almost } \\
\text { feel physically sick }\end{array}$ & 1 & 0.7 \\
\hline \multicolumn{3}{|c|}{$\begin{array}{l}\text { Waiting in chair while dentist and assistants are } \\
\text { taking out dental equipment }\end{array}$} \\
\hline Relaxed & 63 & 44.4 \\
\hline A little uneasy & 43 & 30.3 \\
\hline Tense & 4 & 2.8 \\
\hline Anxious & 30 & 21.1 \\
\hline $\begin{array}{l}\text { So anxious that I sometimes } \\
\text { break out in sweat or almost } \\
\text { feel physically sick }\end{array}$ & 2 & 1.4 \\
\hline \multicolumn{3}{|l|}{ Total DAS } \\
\hline$<7$ & 99 & 69.7 \\
\hline 7-9 & 33 & 23.2 \\
\hline $10-11$ & 5 & 3.5 \\
\hline$>11$ & 5 & 3.5 \\
\hline Total & 142 & 100 \\
\hline
\end{tabular}

Average DAS scores were compared across ages less than or above 40 at different time instances, the differences were not significant. The anxiety scores of males and females were similar as shown by average 
DAS scores. Use of NSAIDs did not differentiate the anxiety of the patients who were to undergo dental procedures. It did not show marked differences in DAS scores of those patients who perceived that they were thoroughly explained by the staffs about the procedures as compared those who perceived that they were not

Table 2. Comparison of DAS scores as per various characteristics.

\begin{tabular}{|c|c|c|c|}
\hline \multirow[b]{2}{*}{ DAS item } & Mean \pm SD & Mean \pm SD & \multirow[t]{2}{*}{$\mathrm{p}$-value } \\
\hline & Age $<40(n=80)$ & Age $>=40(n=62)$ & \\
\hline Anticipation prior to dental treatment & $1.35 \pm 0.89$ & $1.45 \pm 0.90$ & 0.503 \\
\hline Waiting in dental waiting area & $2.09 \pm 1.33$ & $1.87 \pm 1.14$ & 0.308 \\
\hline $\begin{array}{l}\text { Waiting in chair while dentist and assistants are } \\
\text { taking out dental equipments }\end{array}$ & $2.12 \pm 1.27$ & $1.95 \pm 1.12$ & 0.397 \\
\hline \multirow[t]{2}{*}{ Total DAS } & $5.56 \pm 2.80$ & $5.27 \pm 2.46$ & 0.523 \\
\hline & Female $(\mathrm{n}=88)$ & Male $(n=54)$ & \\
\hline Anticipation prior to dental treatment & $1.48 \pm 0.97$ & $1.26 \pm 0.73$ & 0.131 \\
\hline Waiting in dental waiting area & $2.15 \pm 1.28$ & $1.74 \pm 1.17$ & 0.06 \\
\hline $\begin{array}{l}\text { Waiting in chair while dentist and assistants are } \\
\text { taking out dental equipments }\end{array}$ & $2.15 \pm 1.22$ & $1.89 \pm 1.18$ & 0.215 \\
\hline \multirow[t]{2}{*}{ Total DAS } & $5.77 \pm 2.81$ & $4.89 \pm 2.29$ & $0.043^{*}$ \\
\hline & Used NSAIDs $(n=45)$ & Not used NSAIDs $(\mathrm{n}=97)$ & \\
\hline Anticipation prior to dental treatment & $1.53 \pm 0.94$ & $1.33 \pm 0.86$ & 0.223 \\
\hline Waiting in dental waiting area & $2.07 \pm 1.34$ & $1.96 \pm 1.22$ & 0.634 \\
\hline $\begin{array}{l}\text { Waiting in chair while dentist and assistants are } \\
\text { taking out dental equipments }\end{array}$ & $2.02 \pm 1.23$ & $2.06 \pm 1.20$ & 0.856 \\
\hline \multirow[t]{2}{*}{ Total DAS } & $5.62 \pm 2.66$ & $5.35 \pm 2.66$ & 0.572 \\
\hline & $\begin{array}{r}\text { Staffs explained } \\
\text { surgical procedure } \\
\text { in detail }(n=95)\end{array}$ & $\begin{array}{r}\text { Staffs not explained } \\
\text { surgical procedure in } \\
\text { detail }(n=47)\end{array}$ & \\
\hline Anticipation prior to dental treatment & $1.39 \pm 0.87$ & $1.4 \pm 0.95$ & 0.929 \\
\hline Waiting in dental waiting area & $2.08 \pm 1.29$ & $1.81 \pm 1.17$ & 0.218 \\
\hline $\begin{array}{l}\text { Waiting in chair while dentist and assistants are } \\
\text { taking out dental equipments }\end{array}$ & $2.06 \pm 1.19$ & $2.02 \pm 1.24$ & 0.846 \\
\hline Total DAS & $5.54 \pm 2.62$ & $5.23 \pm 2.73$ & 0.524 \\
\hline *Statistically significant & & & \\
\hline
\end{tabular}

explained about the procedures (Table 2).

\section{DISCUSSION}

Studies stated that 3-20\% of the population have fear of dental treatment. ${ }^{2,14}$ Even if they visit the dentist, it is hard to manage such patients. ${ }^{2}$ Our clinical experiences revealed that many patients are scared of oral surgical procedure specially dental extraction compared to other dental procedures. Stress anxiety and various behavioral and emotional changes are commonly expressed by patients during various dental procedures.

Patients undergoing dental procedures may get anxious due to dental surroundings such as dental chair, instruments, and dentists with masks and gloves. Usually it is believed that dental anxiety and fear is related to the stimuli like drilling and injections..$^{3-5}$ They may get anxious while waiting for the appointment with dentist. Anxious patients feel more pain and treatment of longer duration than less anxious patient. ${ }^{6}$

The sex difference in dental anxiety had been reported in several studies. Females are more anxious than male about the dental anxiety score.7-9

A study discussed that females (56.1\%) were more anxious than males (43.9\%). ${ }^{10}$ But in another study the sex differentials were not obvious. ${ }^{5}$ This study did not show differences in anxiety scores of men and women. While comparing the percent of women and men having at least some level of anxiety indicated by anxiety scores of at least 2, 15.9\% women as compared to $9.3 \%$ men anticipated some sort of unusual outcome of their dental procedure. When waiting at waiting area, $54.5 \%$ women 
reported the anxiety as compared to $35.2 \%$ men and this difference is significant $(p=0.025)$. Again at dental chair, the gender differences for feeling of anxiety did not differ significantly (59.1\% women and 50\% men, $\mathrm{p}=0.29$ ). This sort of gender variation while at waiting area may be because at waiting area, patients may have more leisure time to think upon their upcoming dental procedures. Psychological studies indicate that women have a lower pain threshold than men and low tolerance for painful stimuli and this may be the reason for gender difference in dental anxiety. ${ }^{1}$ At the waiting area, women might got more time to think upon the procedure which might have been the cause of higher level of anxiety for them while men indulge themselves in playing games in mobile as reported by the dental assistants in an informal chat.

Many studies have shown that the anxiety level decreases with age. ${ }^{1,10-12}$ The present study did not show differences in anxiety scores of patients of $<40$ years of age as compared to $>=40$ years of age. The age effect has been denied by some and they argued that the anxiety may occur in any age group of people. ${ }^{10}$ Another study supported this evidence and showed that anxiety scores were not different across ages. ${ }^{15}$

The present study compared the DAS scores for those patients who were receiving NSAIDs and those who were not, the differences were not obvious. It is believed that if proper counseling is given, it would help to relieve the anxiety of the patients. In this study, we tried to explore the DAS score differences of patients who reported that they were detailed about the surgical procedures and those patients who said they were not detailed. The DAS scores were not significantly different for these groups. Some arguments are there that Dentist's behavior and communication with patient and explanation about the procedure plays important role in patient's anxiety level. ${ }^{13}$

Actually what we measure is the perceived feeling of a patient about how the procedure has been detailed to them. In informal talk with the dental staffs, they said that they always detail the patient thoroughly.

As this study involves many operators for oral surgical procedures, the inter-performer variations may have their effects which has not been dealt in. Further, as study set up was in Teaching hospital, this study did not explore the variations created by the private clinic environment. Similarly, the study did not look upon the scenario of various departments of dental sciences and focused only on oral surgical procedures. This study could not use random sampling technique.

\section{CONCLUSIONS}

Few patients feared the outcomes of the oral surgical procedure but the anxiety increases as they proceed to waiting area and dental chair. The fear is similar irrespective of the age and gender of the patients.

\section{REFERENCES}

1. Mehboob B, Khan E, Khan M. Dental anxiety scale in exodontias patients. Journal of Khyber College of Dentistry. 2011;1:66-70.[Full Text]

2. Udoye CI, Oginni AO, Oginni FO. Dental anxiety among patients undergoing various dental treatments in a nigerian teaching hospital. J Contemp Dent Pract. 2005; 6(2): 1-8. [Full Text]

3. Attaullah, Khan AA. Prevalence of dental anxiety among university students in Islamabad, Pakistan. Journal of Khyber College of Dentistry. 2011; 2: 71-77.[Full Text]

4. Taani, DQ. Dental attendance and anxiety among public and private school children in Jordan. International Dental Journal. 2002; 52: 25-29.[Full Text]

5. Khokhar NA, AbdullahJ, ShinwariMS, AnwarA,Farid H. Dental fear and anxiety among orthodontic patients - A Pakistani sample. Pakistan Oral and Dental Journal. 2015 June; 35( 2): 220-223.[Full Text]

6. Arigbede AD, Ajayi DM, Adeyemi BF, Kolude B. Dental anxiety among patients visiting a university dental centre. Nigeria Dent J. 2011;19:20-4.[Full Text]

7. Nair MA, Shankarapillai R, Chouhan V. The dental anxiety levels associated with surgical extraction of tooth. Int J Dent Clin. 2009;1:20-3.[Full Text]

8. Oosterink FM, De Jongh A, Hoogstraten J. Prevalence of dental fear and phobia relative to other fear and phobia subtypes. Eur J Oral Sci. 2009; 117: 135-43.[Full Text]

9. Al-Omari WM, Al-Omiri MK. Dental anxiety among university students and its correlation with their field of study. J Appl Oral Sci. 2009; 17: 199-203.[Full Text]

10. Ganesh R, Goswami C, Munshi R. Comparison of dental anxiety among patients visiting a dental college and private dental clinics in Thiruvallur district, India. SRM Journal of Research in Dental Sciences. 2014;5(1):14-20.[Full Text]

11. Appukuttan D, Datchnamurthy M, Deborah PS, Hirudayaraj JG,Tadepalli A, Victor JD. Reliability and validity of Tamil version of modified dental anxiety scale. J Oral Sci. 2012;54:313-20.[Full Text] 
12. Locker D, Liddell A, Dempster L, Shapiro D. Age of onset of dental anxiety. J Dent Res. 1999;78:790-6.[PubMed]

13. Levin L, Eli I, Ashkenzazi M. Dental anxiety among young israeli male adults as related to treatment received during childhood. J Public Health Dent. 2006;66:147-51.[Full Text]

14. Milgrom P, Fiset L, Menick S, Weinstein P.The prevalence and practice management consequences of dental fear in a major us city. J Am Dent Assoc. 1988; 116:641-647.[Full $\underline{\text { Text] }}$
15. Hülya E,ZühreZA,Emre B.Dental fear and anxiety levels of patients attending a dental clinic.Quintessence Int. 2006;37(4):304-10.[PubMed] 